\title{
Influência de diferentes cultivos e fatores climáticos na ocorrência de crisopídeos em sistema agroecológico
}

\author{
Influence of different crops and climate factors on the occurrence of green \\ lacewings in agroecological system
}

\author{
André Luis Santos Resende ${ }^{1 *}$, Brígida Souza', Elen de Lima Aguiar-Menezes², \\ Rafael José Oliveira', Maria Emilia Souzalima Campos ${ }^{2}$
}

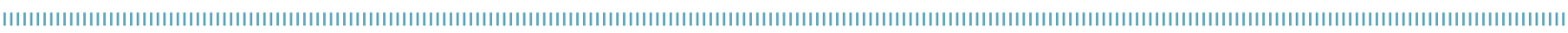

\begin{abstract}
RESUMO: Os insetos predadores da família Chrysopidae têm sido relatados tanto em ecossistemas naturais como nos agroecossistemas, sejam eles cultivos consorciados ou monocultivos. Porém, são escassas as informaçóes sobre o comportamento das populaçóes desses insetos nos agroecossistemas diversificados, como aqueles de base agroecológica. O presente trabalho teve o objetivo de determinar a riqueza de espécies de crisopídeos e avaliar a influência de diferentes cultivos agrícolas, assim como de fatores climáticos na abundância desses insetos em sistema de produçáo orgânica diversificada. $\mathrm{O}$ estudo foi conduzido de setembro de 2008 a agosto de 2009, por meio de amostragens semanais de adultos de Chrysopidae em áreas do Sistema Integrado de Produção Agroecológica, em Seropédica (RJ), cada qual com um tipo de sistema de cultivo (rotação milho-mucuna/olerícolas, cafeeiros sombreados e rotaçáo cana-de-açúcar/pastagem de braquiária). Um total de 424 espécimes de crisopídeos foi coletado, sendo distribuídos em três espécies: Chrysoperla externa (98,1\%), Ceraeochrysa cubana $(1,7 \%)$ e Ceraeochrysa paraguaria $(0,2 \%)$. Não houve diferença no número de adultos coletados em função dos diferentes cultivos, embora a análise de correlação evidencie que as rotaçôes com poáceas favoreçam o aumento da sua abundância. A abundância dos crisopídeos foi influenciada pelo clima apenas no sistema de cafeeiros sombreados, sendo correlacionada negativamente com a temperatura média do ar e a com a precipitação pluvial acumulada.
\end{abstract}

PALAVRAS-CHAVE: Neuroptera; Chrysopidae; dinâmica populacional; manejo do habitat; fatores abióticos.

\begin{abstract}
The green lacewings (Chrysopidae) have been reported in natural ecosystems as well in agroecosystems, intercropping or monocropping. However, the knowledge on their behavior on different agroecosystems is scarce. The present work aimed to determine the diversity of green lacewing species and to evaluate the influence of different agricultural crops, as well as climate factors, on the abundance of these insects in an agroecologically-based organic production system. The study was conducted from September 2008 to August 2009, by performing weekly sampling of Chrysopidae adults in areas of the Integrated Production Agroecological System (SIPA) in Seropédica (RJ), each with one type of cropping system (corn-mucuna rotation/vegetable crops; shaded coffees and sugar cane/brachiaria pasture rotation). A total of 424 adult specimens were collected, belonging to three species: Chrysoperla externa (98.1\%), Ceraeochrysa cubana (1.7\%) and Ceraeochrysa paraguaria $(0.2 \%)$. There were no differences on the number of green lacewing adults collected in the crops, although the correlation analysis showed that the crop rotations with grasses favor their abundance. The abundance of green lacewings was also influenced by the climate conditions only in the system of shaded coffees, being negatively correlated with mean air temperature and accumulated rainfall.
\end{abstract}

KEYWORDS: Neuroptera; Chrysopidae; population dynamics; habitat management; abiotic factors.

'Departamento de Entomologia; Universidade Federal de Lavras (UFLA) - Lavras (MG), Brasil.

${ }^{2}$ Departamento de Entomologia e Fitopatologia; Instituto de Biologia da Universidade Federal Rural do Rio de Janeiro (UFRRJ) - Seropédica (RJ), Brasil.

*Autor correspondente: alsresende@yahoo.com.br

Recebido em: 27/10/2012. Aceito em: 15/07/2014 


\section{INTRODUÇÃO}

A agricultura fundamentada nos princípios da agroecologia pressupóe unidades de produção mais diversificadas no tempo e no espaço, para promover a agrobiodiversidade e os processos biológicos naturais, como o controle biológico de pragas. Vários estudos mostram que sistemas agrícolas diversificados podem favorecer o aumento da riqueza de espécies e/ou a abundância dos inimigos naturais das pragas agrícolas. Contudo, a maioria das pesquisas tem sido conduzida nos Estados Unidos da América, na Europa, na Nova Zelândia e na Austrália (Altieri et al., 2003; ZeHnder et al., 2007). Dessa forma, como os efeitos da diversificação vegetal sobre a fauna não podem ser generalizados, torna-se necessário gerar conhecimento sobre as condiçóes dos agroecossistemas brasileiros.

Entre os inimigos naturais de insetos e ácaros fitófagos, encontram-se os predadores pertencentes à família Chrysopidae (Neuroptera). Esses insetos apresentam grande capacidade de busca, alta voracidade e elevado potencial reprodutivo, além de alimentarem-se de ampla diversidade de presas (CARVALHO; SouZA, 2000). Assim, são organismos que devem ser conservados nos agroecossistemas por desempenharem importante papel no controle biológico natural de artrópodes fitófagos. Apresentam grande plasticidade ecológica, encontrando-se associados aos mais variados tipos de plantas em diferentes extratos da vegetação, embora exista certa especialização em relação às espécies vegetais (Freitas, 2002).

A maioria das espécies de crisopídeos é arborícola, e está predominantemente associada a plantas de porte arbóreo nos ecossistemas naturais, onde normalmente a riqueza de espécies é elevada (Freitas, 2002; Costa et al., 2010). Em fragmentos de floresta estacional semidecídua da regiáo do Alto do Rio Grande, no estado de Minas Gerais, por exemplo, 26 espécies de crisopídeos foram catalogadas (Souza et al., 2008; Costa et al., 2010). No entanto, esses insetos também são capazes de explorar os habitats agrícolas, inclusive monocultivos, como as espécies dos gêneros Chrysoperla Steinmann e Ceraeochrysa Adams (Duelli, 2001; Freitas; Penny, 2001; Freitas, 2002; Barbosa et al., 2004), associando-se a culturas anuais e de porte herbáceo, como as de algodáo, milho, pimenta e pimentáo (Freitas; Penny, 2001; Freitas, 2002) ou a culturas perenes e de porte arbustivo, a exemplo do cafeeiro (Silva et al., 2006) e fruteiras (Gitirana Neto et al., 2001; Souza; Carvalho, 2002; Barbosa et al., 2004; Ribeiro et al., 2009). Além desses ambientes, podem ocorrer em florestas implantadas (CARDOso et al., 2003) e sistemas silvipastoris, nos quais se associam às pastagens (Costa, 2006; Oliveira et al., 2012). Todavia, a riqueza de espécies nesses cultivos, principalmente nos monocultivos, é menor.

Além da influência da vegetação no comportamento das espécies de crisopídeos presentes nos agroecossistemas, os fatores climáticos, como temperatura, umidade relativa do ar e fotoperíodo, também afetam a dinâmica das populaçóes desses predadores. Os estudos de Gitirana Neto et al. (2001) e de Souza; Carvalho (2002) demonstraram, respectivamente, que os picos populacionais de espécies de Ceraeochrysa e Chrysoperla externa (Hagen, 1861), presentes em pomares de citros em Lavras (MG), ocorrem nos períodos de baixas temperaturas e precipitaçōes pluviais (maio a setembro). Contrariamente, em plantios de Pinus taeda, no sul do Paraná, os picos populacionais dos crisopídeos ocorrem nos meses mais quentes (dezembro a março), sendo que, em meses com temperaturas mais baixas (entre 10,8 e $15,5^{\circ} \mathrm{C}$ ), algumas espécies não são coletadas (CARDoso et al., 2003).

O presente estudo objetivou determinar a riqueza de espécies de crisopídeos e avaliar a influência de diferentes cultivos agrícolas e fatores climáticos na ocorrência desses insetos em sistema de produção orgânica conduzido em bases agroecológicas.

\section{MATERIAL E MÉTODOS}

O estudo foi conduzido em áreas do Sistema Integrado de Produção Agroecológica (SIPA), no município de Seropédica

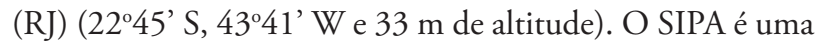
unidade de pesquisa de produção orgânica vegetal e animal integrada, conduzida em bases agroecológicas desde 1993. A área de produção vegetal tem 25 ha divididos em glebas, que variam de 0,5 a 1 ha, cultivadas com fruteiras e hortaliças (30 a 40 espécies por ano, em consórcio simultâneo ou rotação). Não sấo utilizados agrotóxicos orgânicos sintéticos e fertilizantes químicos solúveis, privilegiando o emprego de cobertura viva do solo e adubação verde com fabáceas e/ou poáceas e compostos orgânicos. Somam-se à área de produçáo vegetal 30 ha de fragmento de Mata Atlântica preservada e 15 ha de pastagens (Neves et al., 2005).

Adultos de Chrysopidae foram coletados de setembro de 2008 a agosto de 2009, em três glebas do SIPA, cuja área variou entre 0,5 e 1,0 ha, cada qual com um dos seguintes sistemas de cultivos: 1) rotação milho-mucuna/olerícolas: caracterizado pela rotação de culturas, empregando o cultivo de milho (Zea mays) consorciado com mucuna preta (Mucuna deeringiana), de setembro/2008 a março/2009, sendo substituído por um complexo de hortaliças (couve, brócolis, repolho, alface, cenoura, cebolinha, beterraba, salsa e cebola) cultivadas de abril a agosto/2009; 2) cafeeiros sombreados: café Conilon (Coffea canephora) associado a plantas para sombreamento: fabácea arbórea (Gliricidia sepium) e bananeira (Musa sp. var. Prata Comum); e 3) rotação cana/pastagem: cana-de-açúcar (Saccharum spp.) cultivada desde janeiro/2007, sendo cortada em dezembro/2008, quando foi substituída por pastagem de braquiária (Brachiaria decumbens).

As coletas dos adultos foram realizadas com rede entomológica de tecido voile $(30 \mathrm{~cm}$ de diâmetro e haste de $60 \mathrm{~cm}$ ), em intervalos semanais, no período da tarde (16 h às $18 \mathrm{~h})$, 
e com duraçáo de uma hora, iniciando no centro da área e caminhando em espiral até as bordas. Em laboratório, os insetos coletados foram contados e mortos em congelador. Posteriormente, foram transferidos para frascos de vidro e conservados a seco para identificação específica.

Utilizou-se a análise de correlaçáo dos números totais mensais dos adultos coletados em cada cultivo por meio da determinaçáo do coeficiente de correlação de Pearson, cuja significância foi avaliada pelo teste $t$ de Student.

A flutuação populacional foi graficamente representada, sendo estabelecida a partir do número total de espécimes coletados por mês em cada sistema de cultivo. Avaliou-se a influência da temperatura média do ar, umidade relativa média do ar e precipitação pluvial acumulada no mês sobre a flutuação populacional por meio da determinação do coeficiente de correlaçáo de Pearson, cuja significância foi avaliada pelo teste $t$ de Student. Os dados climáticos mensais foram obtidos na estação meteorológica instalada no SIPA.

\section{RESULTADOS E DISCUSSÃO}

As amostragens resultaram na coleta de 424 adultos de crisopídeos pertencentes a três espécies da subfamília Chrysopinae, sendo 416 espécimes de $C$. externa, sete de Ceraeochrysa cubana (Hagen, 1861) e um de Ceraeochrysa paraguaria (Navás, 1920). A ocorrência dessas espécies já havia sido relatada para agroecossistemas brasileiros (Freitas; Penny, 2001).

Entre os três sistemas estudados, a riqueza foi maior no sistema rotação cana/pastagem, onde foram coletadas três espécies, seguido da rotação milho-mucuna/olerícolas e cafeeiros sombreados, ambos com duas espécies. Menor riqueza de espécies foi observada por Medeiros et al. (2009), que coletaram apenas C. externa em cultivo orgânico de tomate consorciado com coentro, conduzido em área de produção diversificada de hortaliças sob manejo agroecológico, em Brasília (DF). O menor número de espécies de crisopídeos em agroecossistemas em comparação aos ecossistemas naturais já fora relatada por CARDoso et al. (2003). Costa et al. (2010) também observaram maior riqueza de espécies em florestas (26 espécies) do que em ambientes de formaçôes abertas, caracterizados por gradientes entre cerrado, campo rupestre e campos de altitude (12 espécies) e agroecossistemas (três espécies em cafeeiros e uma espécie em pastagem de braquiária).

Como a diversidade de plantas resulta em multiplicidade de nichos ecológicos, esperava-se que ambientes mais diversificados proporcionassem aos crisopídeos mais possibilidades de refúgio e recursos alimentares. Porém, os resultados obtidos apontam que a diversificaçáo vegetal não garante maior riqueza de espécies desses predadores nos agroecossistemas. Altieri et al. (2003) mencionaram que outros fatores, como estímulos visuais ou químicos, mudanças microclimáticas, preferências alimentares ou efeitos diretos do vigor da planta hospedeira, podem influenciar a localização do habitat pelos herbívoros e inimigos naturais e/ou o comportamento de busca deles. Esses autores também alertaram para a adoçáo de uma postura cautelosa e flexível quanto a generalizaçóes, pois as respostas de herbívoros ou inimigos naturais à diversidade vegetal não são uniformes, e nem sempre podem ser explicadas por meio da diversidade por si só.

A predominância de C. externa $(98,1 \%$ dos espécimes coletados) indica que seja uma espécie adaptada a ambientes perturbados, com intensa açáo antrópica, como os agroecossistemas. Esse resultado corrobora as informaçóes de que se trata da espécie de Chrysopidae Neotropical mais comumente encontrada nos agroecossistemas e, na maioria das vezes, a mais abundante (Souza; Carvalho, 2002; Cardoso et al., 2003; Silva et al., 2006; Oliveira et al., 2012).

Entre as três espécies coletadas, $C$. externa foi também a mais constante, ocorrendo durante todo o período de amostragem, portanto, associada a todas as culturas envolvidas nos três sistemas de cultivo. Esse resultado demonstra que esse crisopídeo apresenta maior plasticidade ecológica do que as outras duas espécies coletadas, exibindo, portanto, pouca especialização em relação às espécies vegetais. De acordo com Freitas (2002), C. externa pode ser encontrada ao longo de todos os meses do ano, sendo associada a várias culturas, embora relate sua preferência por poáceas, incluindo as invasoras, nas quais os adultos buscam seu alimento (pólen).

Os sete exemplares de C. cubana foram coletados durante a primavera (setembro a novembro/2008) e início do veráo (dezembro/2008), sendo a maioria proveniente da gleba cultivada com cana-de-açúcar, onde dois indivíduos foram capturados em setembro, dois em outubro e um em novembro. Os outros dois exemplares foram coletados em milho (novembro) e em cafeeiros sombreados (dezembro). No sul de Minas Gerais, Costa (2006) também observou a ocorrência de C. cubana em monocultivo de cafeeiros. Nesse ambiente, outras duas espécies foram coletadas [C. externa e Ceraeochrysa tucumana (Navás, 1919)], observando-se maior riqueza de espécies do que a constatada nos cafeeiros sombreados, onde o grupo foi representado por $C$. externa e C. cubana. A presença dessas duas espécies em cultivos de milho já fora relatada por Freitas; Penny (2001).

O único exemplar de C. paraguaria foi coletado em outubro de 2008, no cultivo de cana-de-açúcar. Essa espécie já havia tido sua ocorrência registrada para agroecossistemas brasileiros, porém, associada a culturas perenes e arbustivas, como goiabeira e citros (Freitas; Penny, 2001). Quando a cana-de-açúcar foi cortada e a gleba ficou ocupada com pastagem, coletaram-se apenas exemplares de C. externa, a qual também foi a única espécie coletada por Costa (2006) e Oliveira et al. (2012) em área de pastagem de braquiária. Em geral, espécies do gênero Chrysoperla ocorrem mais frequentemente em habitats de vegetação rasteira do que outros gêneros de Chrysopidae (Duelli, 2001). 
Os adultos de C. externa foram coletados em maior número ( $\mathrm{n}=163)$ na gleba com sistema de rotação de cana-de-açúcar e pastagem, seguida da gleba com sistema de rotaçáo milho-mucuna/olerícolas, onde foram coletados 145 adultos, e, em menor número, na gleba com cafeeiros sombreados (116 adultos).

A análise de correlação evidenciou que apenas os cultivos envolvendo rotação com poáceas (milho-mucuna/olerícolas e cana/pastagem) apresentaram correlação positiva e significativa (Tabela 1). Esses resultados demonstram que esses sistemas de cultivo favorecem o aumento da densidade populacional de crisopídeos, os quais foram representados, em sua maioria, por C. externa. Sugerem, ainda, a preferência dessa espécie por habitats com plantas de porte herbáceo, conforme salientado por Duelli (2001). Ademais, a maior ocorrência dos crisopídeos nesses sistemas de rotação também pode ter sido favorecida pela presença de poáceas, principalmente na época do florescimento, haja vista o fato de o pólen desses vegetais ser preferido como recurso alimentar pelos adultos desses insetos, a exemplo de C. externa (Freitas, 2002).

Todavia, independentemente dos cultivos, os adultos de crisopídeos foram mais abundantes no mês de outubro, quando ocorreram os picos populacionais nos três sistemas estudados (Fig. 1). O maior número de espécimes coletados foi de C. externa. Nesse mês, coletou-se um total de 99 espécimes de crisopídeos, e as glebas com sistema de rotação estavam ocupadas por milho/mucuna ou cana-de-açúcar. $\mathrm{O}$ mês de outubro foi caracterizado por temperatura média do ar de $23,4^{\circ} \mathrm{C}$, umidade relativa do ar de $83,77 \%$ e precipitação pluvial acumulada de $98 \mathrm{~mm}$.

Em cafeeiros cultivados a pleno sol sob manejo orgânico, no município de Santo Antonio do Amparo (MG), Silva et al. (2006) observaram que o pico populacional de C. externa ocorreu em setembro de 2001 e 2003, quando a temperatura média alcançou valores em torno de 17 e $23^{\circ} \mathrm{C}$, respectivamente. Porém, igualmente ao observado no presente estudo, houve uma queda brusca na densidade populacional de adultos dessa espécie no período de novembro a março, a qual foi mais drástica no mês de janeiro. Em Anagé, no semiárido do estado da Bahia, C. externa foi mais abundante nos pomares de manga entre agosto e setembro, quando as temperaturas variaram entre 15 e $23^{\circ} \mathrm{C}$ (RiBEIro et al., 2009).

Nos fragmentos de floresta estacional semidecidual da região do Alto do Rio Grande (MG), as populaçóes de crisopídeos aumentaram a partir de agosto, com picos em dezembro de 2003 e 2004, cujas temperaturas médias giraram ao redor de $23^{\circ} \mathrm{C}$ (Costa, 2006). Em cultivo de erva-mate no município de São Mateus do Sul (PR), esses insetos foram registrados apenas nos meses de janeiro e fevereiro (LeITe et al., 2007).

Assim, o pico populacional de crisopídeos em ambientes cultivados ocorre entre os meses de agosto e outubro, como relatado por SiLva et al. (2006) e Ribeiro et al. (2009), período em que C. externa é dominante. Já em ambientes naturais, onde
Tabela 1. Coeficiente de correlação de Pearson ( $r$ ) entre os números totais mensais de adultos de crisopídeos coletados em glebas com diferentes cultivos no Sistema Integrado de Produção Agroecológica (SIPA). Seropédica, RJ, setembro de 2008 a agosto de 2009.

\begin{tabular}{lc} 
Sistemas de cultivos & $\mathbf{r}$ \\
Cana/Pastagem x Cafeeiros Sombreados & 0,3741 \\
\hline $\begin{array}{l}\text { Cafeeiros Sombreados x Milho-Mucuna/ } \\
\text { Olerícolas }\end{array}$ & 0,4637 \\
\hline Cana/Pastagem x Milho-Mucuna/Olerícolas & $0,8701^{*}$ \\
\hline
\end{tabular}

*Significativo a $1 \%$ de probabilidade pelo teste $t$ de Student.

ocorrem diferentes espécies de crisopídeos, o pico populacional ocorre em dezembro, para aquelas presentes em formaçóes florestais fechadas, como em Floresta Estacional Semidecidual, e em fevereiro e março para as espécies que habitam formaçôes florestais abertas (Costa et al., 2010). Essas informaçóes evidenciam as divergências nos picos populacionais de crisopídeos em função do ambiente que ocupam.

De forma geral, durante o período de amostragem náo houve grandes variaçóes nos valores de umidade relativa do ar (88,20\% em novembro/2008 a 78,75\% em fevereiro/2009) e de temperatura média do ar $\left(26,98^{\circ} \mathrm{C}\right.$ em fevereiro/2009 a $19,56^{\circ} \mathrm{C}$ em setembro/2008), enquanto para a precipitação pluvial registrou-se o máximo de 255,80 mm em dezembro/2008 e o mínimo de $31,40 \mathrm{~mm}$ em agosto/2009. O aumento no volume de chuvas ocorridas a partir de outubro/2008 foi acompanhado por uma queda gradativa na densidade populacional dos crisopídeos. Em janeiro/2009, quando a precipitação pluvial foi de $235,80 \mathrm{~mm}$, não foi coletado nenhum exemplar na gleba cultivada com cafeeiros sombreados, e houve drástica redução no número daqueles coletados na área cultivada com milho consorciado com mucuna. No sistema cana/pastagem, a menor densidade populacional de adultos de crisopídeos ocorreu em fevereiro/2009, quando houve uma queda acentuada no volume de chuvas. Em Lavras (MG), Souza; Carvalho (2002) também registraram baixa ocorrência de C. externa no verão (dezembro, janeiro e fevereiro), porém, a queda na densidade populacional do crisopídeo foi correlacionada a temperaturas e precipitaçóes pluviais mais elevadas.

Em estudo sobre as exigências térmicas de C. externa, Maia et al. (2000) demonstraram que o tempo de desenvolvimento das fases imaturas está inversamente correlacionada com a temperatura, sendo mais curto a $30^{\circ} \mathrm{C}$. Entre as temperaturas estudadas, a faixa de 24 a $30^{\circ} \mathrm{C}$ foi a mais favorável para o desenvolvimento dessa espécie. Esses resultados podem explicar a grande variação mensal no total de adultos de crisopídeos capturados nos diferentes sistemas, variando de nenhum exemplar coletado em cafeeiros sombreados (janeiro/2009) a 45 exemplares coletados em cana/pastagem (outubro/2008), haja vista as temperaturas médias mensais terem variado de 19 a $27^{\circ} \mathrm{C}$. 


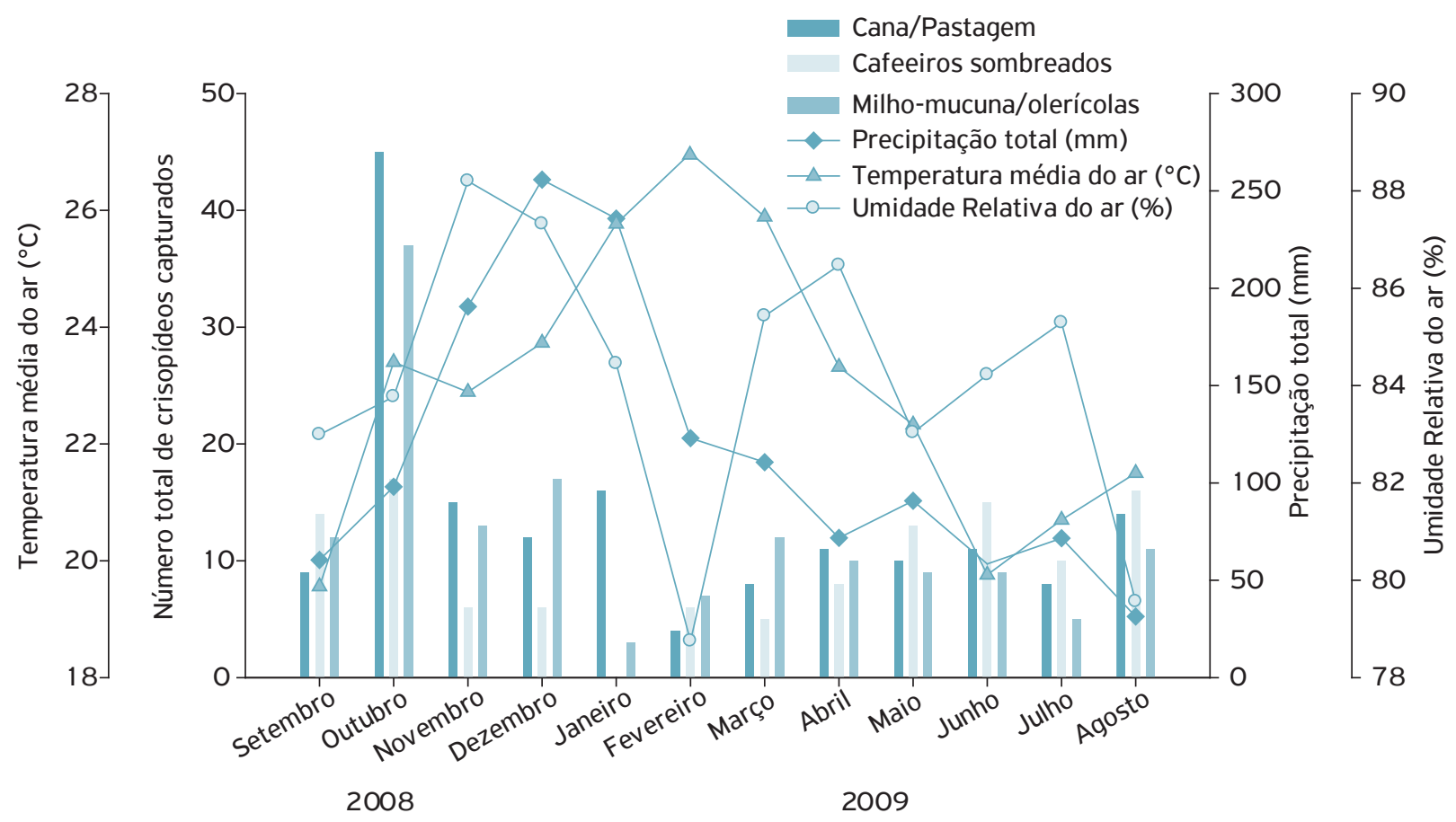

Figura 1. Flutuação populacional de adultos de crisopídeos coletados em glebas com diferentes cultivos e variação mensal de fatores climáticos no Sistema Integrado de Produção Agroecológica (SIPA). Seropédica, RJ, setembro de 2008 a agosto de 2009.

Considerando-se as variáveis macroclimáticas, constata-se que grande parte das interaçôes entre os fatores do clima e os sistemas de cultivo incluídos no estudo não apresentou correlação com a densidade populacional dos adultos dos crisopídeos presentes nos sistemas anuais de rotação (Tabela 2). Em Coronel Pacheco (MG), Oliveira et al. (2012) também não observaram influência da umidade relativa do ar na densidade populacional de crisopídeos em pastagem de braquiária; porém, os picos populacionais dos adultos de C. externa associados a essa poácea foram negativamente correlacionados com as temperaturas médias do ar e as precipitaçóes pluviais.

No sistema de cafeeiros sombreados houve correlação negativa significativa com a temperatura média do ar e a precipitação pluvial acumulada (Tabela 2), demonstrando que, em nível macroclimático, o aumento nos valores desses parâmetros resulta no decréscimo da densidade populacional dos adultos de crisopídeos, e vice-versa. Em cafeeiros em sistemas convencional e orgânico, Silva et al. (2006) também constataram uma redução no número de adultos de C. externa em função do aumento do volume de chuvas e da temperatura média do ar. Comportamento semelhante das populaçóes de crisopídeos foi observado em outras culturas de porte arbustivo. Em cultivos de citros, em Lavras (MG), por exemplo, Gitirana Neto et al. (2001) e Souza; Carvalho (2002) observaram, respectivamente, que as maiores densidades populacionais de Ceraeochrysa spp. e C. externa, ocorreram em meses com temperaturas médias do ar e precipitaçóes pluviais mais baixas. Segundo os autores, os fatores do clima
Tabela 2. Coeficiente de correlação de Pearson ( $r$ ) entre os dados climáticos e os números totais mensais de adultos de crisopídeos coletados em glebas com diferentes cultivos, no Sistema Integrado de Produção Agroecológica (SIPA). Seropédica, RJ, setembro de 2008 a agosto de 2009.

\begin{tabular}{lccc} 
Cultivos & $\begin{array}{c}\text { Temperatura } \\
\text { média do ar } \\
\left({ }^{\circ} \mathrm{C}\right)\end{array}$ & $\begin{array}{c}\text { Umidade } \\
\text { relativa do } \\
\text { ar }(\%)\end{array}$ & $\begin{array}{c}\text { Precipitação } \\
\text { pluvial } \\
\text { acumulada } \\
(\mathrm{mm})\end{array}$ \\
$\begin{array}{l}\text { Milho-Mucuna/ } \\
\text { Olerícolas }\end{array}$ & $-0,0180$ & 0,2659 & 0,0467 \\
\hline $\begin{array}{l}\text { Cafeeiros } \\
\text { sombreados }\end{array}$ & $-0,6664^{*}$ & $-0,3496$ & $-0,6735^{*}$ \\
\hline $\begin{array}{l}\text { Cana/ } \\
\text { Pastagem }\end{array}$ & 0,0050 & 0,1878 & 0,0900 \\
\hline
\end{tabular}

*Significativo a $1 \%$ pelo teste $t$ de Student.

podem ser limitantes, não somente para a ocorrência, como também para a sobrevivência desses insetos em condiçôes naturais. Em pomares de goiaba, em Campos dos Goytacazes (RJ), MulTANi (2008) também observou correlação negativa entre a temperatura média do ar e a precipitação pluvial com as flutuaçôes populacionais de crisopídeos, registrando-se o aumento da abundância relacionado à queda da temperatura e do volume de chuvas. Por outro lado, na regiáo do Alto do Rio Grande (MG), Costa (2006) observou correlaçấo positiva entre a temperatura média do ar e o número total de crisopídeos coletados em fragmentos de floresta estacional semidecidual e em ambientes de formaçóes abertas, onde a 
maior abundância desses insetos ocorreu em períodos mais quentes do ano.

\section{CONCLUSÕES}

Os adultos de crisopídeos ocorrem indiscriminadamente em diferentes cultivos agrícolas, tendendo a apresentar maior abundância nas áreas cultivadas com poaceas. Em agroecossistemas diversificados, a influência dos fatores climáticos sobre a densidade populacional dos crisopídeos varia com o sistema de cultivo.

\section{AGRADECIMENTOS}

Os autores agradecem ao Prof. Dr. Renildo Ismael Félix da Costa, do Instituto Federal de Educação, Ciência e Tecnologia do Norte de Minas Gerais - Campus Januária, pela identificação específica dos insetos da família Chrysopidae. Ao Conselho Nacional de Desenvolvimento Científico e Tecnológico (CNPq), à Fundação de Amparo à Pesquisa do Estado de Minas Gerais (FAPEMIG), à Fundação de Amparo à Pesquisa do Estado do Rio de Janeiro (FAPERJ) e à Coordenação de Aperfeiçoamento de Pessoal de Nível Superior (CAPES), pelo auxílio financeiro.

\section{REFERÊNCIAS}

ALTIERI, M.A.; SILVA, E.N.; NICHOLLS, C.I. O papel da biodiversidade no manejo de pragas. Ribeirão Preto: Holos, 2003. 226p.

BARBOSA, M.L.L.; ACIOLI, A.N.S.; OLIVEIRA, A.N.; SILVA, N.M.; CANTO, S.L.O. Ocorrência de Tuthillia cognata Hodkinson, Brown \& Burckhardt, 1986 (Hemiptera: Homoptera, Psyllidae) em plantios experimentais de camu-camu Myrciaria dubia (H.B.K.) McVaugh em Manaus (Amazonas, Brasil). Acta Amazonica, v.34, n. 1, p.1 15-1 19, 2004.

CARDOSO, J.T.; LÁZZARI, S.M.N.; FEITAS, S.; IEDE, E.T. Ocorrência e flutuação populacional de Chrysopidae (Neuroptera) em áreas de plantio de Pinus taeda (L.) (Pinaceae) no sul do Paraná. Revista Brasileira de Entomologia, v.47, n.3, p.473-475, 2003.

CARVALHO, C.F.; SOUZA, B. Métodos de criação e produção de crisopídeos. In: BUENO, V.H.P. (Ed.). Controle biológico de pragas: produção massal e controle de qualidade. Lavras: UFLA, 2000. cap.6, p.91-109.

COSTA, R.I.F. Estudo da taxocenose de crisopídeos (Neuroptera: Chrysopidae) em ecossistemas naturais e agropastoris. 2006. 124f. Tese (Doutorado em Entomologia) - Universidade Federal de Lavras, Lavras, 2006.

COSTA, R.I.F.; SOUZA, B.; FREITAS, S. Dinâmica espaço-temporal de taxocenoses de crisopídeos (Neuroptera: Chrysopidae) em ecossistemas naturais. Neotropical Entomology, v.39, n.4, p.470475, 2010.

DUELLI, P. Lacewings in field crops. In: McEWEN, P.; NEW, T.R.; WHITTINGTON, A.E. Lacewings in the crop environment. New York: Cambridge University Press, 2001. cap.8, p.158-171.

FREITAS, S.O uso de crisopídeos no controle biológico de pragas. In: PARRA, J.R.P.; BOTELHO, P.S.M.; CORRÊA-FERREIRA, B.S.; BENTO, J.M.S. Controle biológico no Brasil: parasitóides e predadores. São Paulo: Manole, 2002. cap.13, p.209-224.

FREITAS, S.; PENNY, N.D. The green lacewings (Neuroptera: Chrysopidae) of Brazilian agro-ecossystems. Proceedings of the California Academy of Sciences, v.52, n. 19, p.245-395, 2001.
GITIRANA NETO, J.; CARVALHO, C.F.; SOUZA, B.; SANTA-CECÍLIA, L.V.C. Flutuação populacional de espécies de Ceraeochrysa Adams, 1982 (Neuroptera: Chrysopidae) em citros, na região de Lavras-MG. Ciência e Agrotecnologia, v.25, n.3, p.550559, 2001.

LEITE, M.S.P.; ZANOL, K.M.; IEDE, E.T.; PENTEADO, S.R.C. Flutuação populacional de Gyropsylla spegazziniana (Lizer y Trelles) (Hemiptera, Psyllidae) e de seus inimigos naturais em erva-mate no município de São Mateus do Sul, PR, Brasil. Revista Brasileira de Entomologia, v.51, n.4, p.520-523, 2007.

MAIA, W.J.M.S.; CARVALHO, C.F.; SOUZA, B. Exigências térmicas de Chrysoperla externa (Hagen, 1861) (Neuroptera: Chrysopidae) alimentada com Schizaphis graminum (Rondani, 1852) (Hemiptera: Aphididae) em condições de laboratório. Ciência e Agrotecnologia, v.24, n. 1, p.81-86, 2000.

MEDEIROS, M.A.; SUJII, E.R.; MORAIS, H.C. Effect of plant diversification on abundance of South American tomato pinworm and predators in two cropping systems. Horticultura Brasileira, v.27, n.3, p.300-306, 2009.

MULTANI, J.S. Diversidade e abundância de crisopídeos (Neuroptera, Chrysopidae) e interações com presas, parasitóides e fatores abióticos em pomares de goiaba em Campos dos Goytacazes, RJ. 2008. 176f. Tese (Doutorado em Produção Vegetal) - Universidade Estadual do Norte Fluminense, Campos dos Goytacazes, 2008.

NEVES, M.C.P.; GUERRA, J.G.M.; CARVALHO, S.R.; RIBEIRO, R.L.D.; ALMEIDA, D.L. Sistema integrado de produção agroecológica ou Fazendinha Agroecológica km 47. In: AQUINO, A.M.; ASSIS, R.L. Agroecologia: princípios e técnicas para uma agricultura orgânica sustentável. Brasília: Embrapa Informação Tecnológica, 2005. cap.6, p.147-172.

Oliveira, S.A.; Auad, A.M.; Souza, B.; Fonseca, M.G.; Resende, T.T. Population dynamics of Chrysoperla externa (Hagen) (Neuroptera: Chrysopidae) in a silvopastoral system. International Journal of Biodiversity and Conservation, v.4, p.4, p.179-182, 2012. 
RIBEIRO, A.E.L.; CASTELLANI, M.A.; FREITAS, S.; NOVAES, Q.S.; PÉREZ-MALUF, R.; MOREIRA, A.A.; SILVA, C.G.V. Análise faunística e ocorrência sazonal de crisopídeos (Neuroptera: Chrysopidae) em pomar comercial de manga (Mangifera indica L.) no semi-árido da região sudoeste da Bahia, Brasil. Boletín de Sanidad Vegetal - Plagas, v.25, n. 1, p. 15-23, 2009.

SILVA, R.A.; REIS, P.R.; SOUZA, B.; CARVALHO, C.F.; CARVALHO, G.A.; COSME, L.V. Flutuação populacional de adultos de Chrysoperla externa (Hagen, 1861) (Neuroptera: Chrysopidae) em cafeeiros conduzidos em sistemas orgânico e convencional. Manejo Integrado de Plagas y Agroecología, n.77, p.44-49, 2006.
SOUZA, B.; COSTA, R.I.F.; LOUZADA, J.N.C. Influência do tamanho e da forma de fragmentos florestais na composição da taxocenose de crisopídeos (Neuroptera: Chrysopidae). Arquivos do Instituto Biológico, v.75, n.3, p.351-358, 2008.

SOUZA, B.; CARVALHO, C.F.Population dynamics and seasonal occurrence of adults of Chrysoperla externa (Hagen, 1861) (Neuroptera: Chrysopidae) in a citrus orchard in Southem Brazil.ActaZoologicaAcademiae Scientiarum Hungaricae, v.48, n.2 (supplement), p.301-310, 2002.

ZEHNDER, G.; GURR, G.M.; KÜHNE, S.; WADE, M.R.; WRATTEN, S.D.; WYSS, E. Arthropod pest management in organic crops. Annual Review of Entomology, v.52, p.57-80, 2007. 